\title{
Formation Kinetics and Viscoelastic Properties of Water/Crude Oil Interfacial Films
}

\author{
C.G. Quintero', C. Noïk ${ }^{1}$, C. Dalmazzone ${ }^{1}$ and J.L. Grossiord² \\ 1 Institut français du pétrole, IFP, 1-4 avenue de Bois-Préau, 92852 Rueil-Malmaison - France \\ 2 Laboratoire de Physique Pharmaceutique, UMR CNRS 8612, 5 rue Jean-Baptiste Clément, 92296 Châtenay-Malabry - France \\ email: carlos.quintero@total.com - christine.noik@ifp.fr - christine.dalmazzone@ifp.fr - jean-louis.grossiord@u-psud.fr
}

Résumé - Cinétique de formation et propriétés viscoélastiques du film interfacial eau/brut pétrolier - Les propriétés viscoélastiques du film interfacial huile/eau ont été étudiées sur un système pétrole brut de type paraffinique/eau salée afin d'en déterminer la cinétique de formation. Un tensiomètre à goutte pendante oscillante a été utilisé pour mesurer la tension interfaciale dynamique ainsi que les modules élastique $\left(E^{\prime}\right)$ et visqueux ( $\left.E^{\prime \prime}\right)$ à différentes températures $\left(20-60^{\circ} \mathrm{C}\right)$ et à plusieurs fréquences $(N)$. L'évolution de ces propriétés a été analysée et les mesures à 15 minutes indiquent que les modules et le déphasage vérifient les critères proposés par Winter et Chambon pour la formation d'une structure organisée à l'interface. L'effet de l'âge de l'interface est discuté sur les valeurs des modules d'élasticité ainsi que l'effet de la température sur les propriétés de surface et de tension interfaciale.

\begin{abstract}
Formation Kinetics and Viscoelastic Properties of Water/Crude Oil Interfacial Films - Viscoelastic interfacial properties of a light paraffinic crude oil/water system were studied in order to determine the formation film kinetics. A drop oscillatory tensiometer was used for measuring the dynamical interfacial tension and elastic ( $\left.E^{\prime}\right)$ / viscous ( $\left.E^{\prime \prime}\right)$ modulus at different temperatures $\left(20-60^{\circ} \mathrm{C}\right)$ and different pulsation frequencies $(N)$. The evolution of these viscoelastic properties is analyzed. Monitoring with time the viscoelastic properties of the interfacial film, our experimental measures after 15 minutes, verified the criterion proposed by Winter and Chambon for the formation of an organized molecular structure. Interface age effect is discussed comparing the values of elasticity moduli, as well as temperature effect on the surface properties and interfacial tension.
\end{abstract}




\section{INTRODUCTION}

During operations of crude oil production, water-in-oil emulsions are naturally produced due to the presence of water in the reservoir, high stirring zones in production facilities and amphiphilic indigenous species in crude oil, like asphaltenes and resins [1-3], but also to organic or inorganic small solids like waxes and sand [4-6]. In spite of the fact that these systems are thermodynamically unstable, they may be very resistant against coalescence, mainly due to their interface characteristics.

Water-in-crude oil emulsions are a main problem in the exploitation of petroleum reservoirs, especially for the high internal volume fraction, where the emulsion viscosity increases significantly. Moreover, salt dissolved in droplets may be very corrosive, and it must be removed before the refining process.

Thus, an exact understanding of mechanisms of coalescence/stability of these systems is a key factor for a good separation process design. Consequently, an important research effort has been carried out for some decades in order to understand how native amphiphiles stabilize emulsions. Nevertheless this mechanism is still yet not well understood.

It is well recognized that emulsion behavior is mostly controlled by the properties of the amphiphilic film that surrounds water droplets in the crude oil. Among these properties, the determination of interfacial tension alone is not sufficient to predict the emulsion behavior. An interfacial tension gradient is induced by resins and asphaltenes, which mainly compose the interfacial film. They behave like a mechanical barrier that avoids coalescence, and confer to the film an elastic character [7-9].

Therefore, many works have been performed in order to associate interfacial rheological properties with emulsion behavior. Several techniques have been applied based on different experimental measurements: with a drop dilation/ compression oscillatory tensiometer [10-16]; with a flat interface by means of a Langmuir Balance $[17,18]$; or a sheared flat interface by means of a rotating/oscillatory interfacial device $[3,19,20]$. Most of the studied systems were model oils or solution of crude oil fractions (i.e. asphaltenes, resins, heavy fractions). Furthermore, many studies have been made using chemical additives for emulsion breaking (demulsifiers) in order to understand the chemical induced separation process [21, 22]. In general, several mechanisms of film formation have been proposed, and a strong correlation between surface viscoelastic properties and emulsion stability has been confirmed.

Among those research results, Bouriat et al. [11] found that solutions of asphaltenes seem to form a two dimension gel at the W/O interface according to the theories developed by Chambon and Winter [23, 24] for a cross linked gel. Those authors made the analogy between classical rheology and interfacial dilational rheology. Later on, Dicharry et al.
[12] found this same behavior for a diluted crude oil and a diluted heavy fraction of this same crude oil. They observed that it is possible to find the gel formation even in the absence of asphaltenes.

Some other authors have studied aged water/crude oil interfaces [25]. They have concluded that the older is the interface, more stable is the emulsion system. On the other hand, it is important to understand the kinetics of film formation, because the ability to create emulsions has been correlated with the rate of change of the interfacial tension [26]. The ability of some amphiphilic molecules to rapidly adsorb may induce the formation of a rigid film since very short times and determine the emulsion stability [27]. So, in oil field operations, according to the characteristics of each system, required times for breaking emulsions are generally very long and chemical agents are needed to fasten it.

In this paper a real crude oil/water interface was studied, in order to follow the kinetics of interfacial film formation in more realistic conditions than other studies with model oils. The low viscosity of this crude oil allowed carrying out dilational rheological measures without difficulty. The evolution with time of the interfacial tension and viscoelastic properties (elastic $E^{\prime}$ and viscous modulus $E^{\prime \prime}$ ) were measured for different frequencies and different temperatures. The age of the interface and temperature effects are also analyzed for this interface.

\section{MATERIALS AND METHODS}

\subsection{Fluids}

A French paraffin crude oil (free of chemical additives) was used with a specific gravity of 0.856 at $30^{\circ} \mathrm{C}\left({ }^{\circ} \mathrm{API}=33.8^{\circ}\right)$. The SARA (Saturates, Aromatics, Resins and Asphaltenes) fractions results are presented in Table 1. A brine prepared with $\mathrm{NaCl}$ (99.5\% w purity) in deionised water (ultra pure degree MilliQ) with a concentration of $8 \mathrm{~g} / \mathrm{L}$ was used as the aqueous phase. The chloride concentration of this reconstituted brine is similar to the one found in the naturally formed crude oil emulsion at the production oil field.

TABLE 1

SARA analysis of the crude oil

\begin{tabular}{c|c}
\hline SARA & Content $(\% \mathrm{wt})$ \\
\hline Saturates & $49.7 \pm 1.1$ \\
\hline Aromatics & $38.0 \pm 1.1$ \\
\hline Resins & $12.9 \pm 1.1$ \\
\hline Asphalthenes & $0.1 \pm 0.0$ \\
\hline
\end{tabular}

Both crude oil and $\mathrm{NaCl}$ solutions were stocked in a temperature controlled atmosphere, according to the 
temperature of the test (mostly $\left.30^{\circ} \mathrm{C}\right)$. Densities were measured with an Anton Paar DMA500 equipment in the range $15-60^{\circ} \mathrm{C}$.

\subsection{Methods}

\subsubsection{Interfacial Tension}

A dynamic interfacial oscillatory drop tensiometer, Tracker, from IT Concept France was used for all the measures. This equipment and its characteristics were comprehensively described previously [28]. The principle of measure is to record in real time the shape of a drop, formed at the end of a syringe needle. The drop (the most opaque fluid, in this case the crude oil) is surrounded with the clearest phase $(\mathrm{NaCl}$ solution) contained in a thermostated glass cell. The drop profile is processed from the digital video signal obtained with a CCD digital camera. The interfacial tension is calculated from the Laplace's equation and the force's balance between capillarity and gravity. The dynamic interfacial tension between the crude oil and the aqueous phase was monitored with time for fresh drops from a time zero (initial contact between phases). Temperature was fixed at $20,30,40,50$ or $60^{\circ} \mathrm{C}$.

\subsubsection{Dilational Rheological Measurements}

The surface dilational elastic modulus $(E)$ with the elastic (conservative or storage modulus) $E$ ' and viscous (dissipative or loss modulus) $E$ " components have been measured with the same oscillatory drop tensiometer. The syringe is connected to an electro-mechanical system controlled by the software, which allows changing the volume of the drop (i.e. the surface) with a sinusoidal profile. The amplitude and the pulsation frequency of this profile are fixed by the user.

A sinusoidal variation of the drop volume (surface) implies a sinusoidal variation of the interfacial tension. The interfacial tension profile is obtained from the surface profile and then the phase angle $\delta$ between surface and tension. Therefore, all the rheological interfacial properties may be calculated with the following equations:

$$
E=\frac{d \gamma}{d \ln A} \text { from Gibbs equation }
$$

Thus, the elastic modulus $E$ ' and viscous modulus $E$ ' are deduced from the interfacial modulus with:

$$
\begin{aligned}
& E^{\prime}=|E| \cos \delta \\
& E^{\prime \prime}=|E| \sin \delta
\end{aligned}
$$

The kinetics related to the interfacial film formation was studied applying sinusoidal deformations with time on fresh drops. In order to study the viscoelastic properties in a linear regime, a surface deformation of $8.7 \%$ or less was applied for all the measures. Different pulsation frequencies were used: from $0.02 \mathrm{~Hz}$ to $1 \mathrm{~Hz}$. These tests were carried out at $T=30^{\circ} \mathrm{C}$. It is worth mentioning that for the highest frequencies (more than $0.5 \mathrm{~Hz}$ ) the quality of measurements is lower, due to the fact that for these frequencies the technical limit of the equipment is almost reached (maximum frequency: $1 \mathrm{~Hz}$ ).

The age of interface was also considered with the purpose of comparing the effect of time between a fresh drop and an aged drop. For that, the drop was kept in contact with the aqueous phase during 14 hours at a fixed temperature of $30^{\circ} \mathrm{C}$. Then, a series of oscillations was performed at different pulsations (from the lowest to the highest) with the same surface deformation of $8.7 \%$.

The effect of temperature was also studied. For this test, a drop was kept in contact with the aqueous phase during $14 \mathrm{~h}$ at $T=15^{\circ} \mathrm{C}$. After that period, a temperature scan was applied with a gradient of $1^{\circ} \mathrm{C} / 15$ minutes while the drop was deformed with a sinusoidal pulsation frequency of $0.1 \mathrm{~Hz}$ and $0.5 \mathrm{~Hz}$.

\subsubsection{Relaxation Test}

The elastic modulus $E(t)$ calculated with the Gibbs Equation could be measured with the same drop tensiometer. For that, it is necessary to apply in a given time $\left(t_{0}\right)$ a rapid linear deformation on the drop, increasing its surface with an imposed surface variation $(\Delta A)$ and to measure the evolution with time of the interfacial tension $\gamma(t)$. In this case, the same surface deformation as applied for the oscillatory deformations was used $(8.7 \%)$. Thus, if the relaxation modulus is normalized with its value at $t_{0}$, Equation (4) gives:

$$
\begin{aligned}
& E(t)=\frac{\left(\gamma(t)-\gamma_{\mathrm{eq}}\right) A}{\Delta A} \text { and } \\
& E_{0}=\frac{\left(\gamma_{0}-\gamma_{\mathrm{eq}}\right) A}{\Delta A} \Rightarrow \frac{E(t)}{E_{0}}=\frac{\gamma(t)-\gamma_{\mathrm{eq}}}{\gamma_{0}-\gamma_{\mathrm{eq}}}
\end{aligned}
$$

So, it is possible to calculate the relaxation modulus with time as a function of the instantaneous interfacial tension $\gamma(t)$, the interfacial tension at equilibrium $\gamma_{\mathrm{eq}}$ and the interfacial tension $\gamma_{0}$ at $t_{0}$.

\section{RESULTS AND DISCUSSIONS}

\subsection{Interfacial Tension}

The effect of temperature on the dynamic interfacial tension is presented in Figure 1. These values correspond to the evolution of the interfacial tension with time at a fixed temperature, from $20^{\circ} \mathrm{C}$ to $60^{\circ} \mathrm{C}$ with a step of $10^{\circ} \mathrm{C}$. For each temperature, a fresh droplet was formed each time.

Interfacial tension decreases rapidly with time within the first minutes and continuously decreases over a long period nearly reaching a plateau value at time over $3000 \mathrm{~s}$. At fixed time, the interfacial tension decreases when temperature increases. 


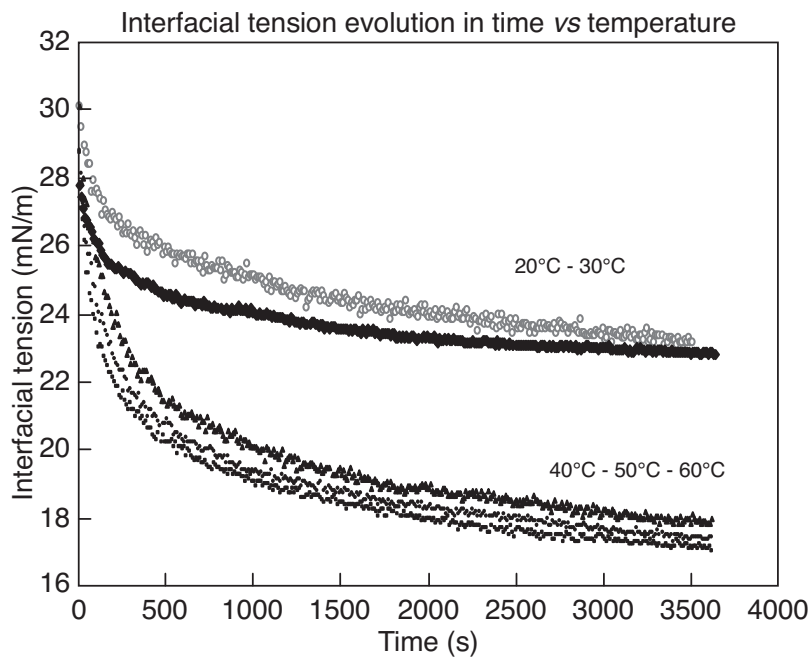

Figure 1.

Interfacial tension $v s$ temperature.

Two kinds of curve profiles were found: for $T \leq 30^{\circ} \mathrm{C}$ and for $T>30^{\circ} \mathrm{C}$, where it is possible to notice a similar tendency for the tension at equilibrium in both cases $\left(T=20\right.$ or $30^{\circ} \mathrm{C}$ and $T=40,50,60^{\circ} \mathrm{C}$ ). From previous studies with this crude oil [29], it was found that crude oil paraffins' crystals threshold of precipitation temperature is $23^{\circ} \mathrm{C}$. Some authors [30] have shown that paraffins may have an influence on the oil/water interfacial properties, which can explain why the dynamic interfacial tension profile is strongly affected by temperature.

Different types of model of the kinetics of adsorption of molecules in the film may be used to adjust the measurements. Firstly a monoexponential model was considered as it has been proposed by Serrien et al. [31] for the proteins' adsorption process:

$$
\gamma(t)=\gamma_{\mathrm{eq}}+\left(\gamma_{0}-\gamma_{\mathrm{eq}}\right) e^{-1 / \tau}
$$

where $\gamma_{\text {eq }}$ is the interfacial tension at equilibrium, $\gamma_{0}$ is the interfacial tension at time zero, and $\tau$ is the characteristic time for the reorganization process of the interfacial film. It can be noticed that the regression line that follows the monoexponential model does not perfectly fit the experimental points. The regression coefficient ( $T a b .2)$ calculated at temperature above $30^{\circ} \mathrm{C}$ are around a medium value around 0.96 and decreases down to 0.91 at $20^{\circ} \mathrm{C}$.

The no perfect fitting with monoexponential model may be associated to several kinds of adsorption processes. Jeribi et al. [32] have found a similar tendency for asphalted model oils. Bouriat et al. [11] have found that for an asphalted model oil, this model does not fit accurately. Actually, for their system, a multiexponential fit in several decades was found leading to consider that the shortest relaxation times correspond to the diffusion process of the asphaltenes from the bulk to the interface and the longer times are related to the rearrangement of the asphaltene molecules at the interface to form the film.

\section{TABLE 2}

Interfacial tension at equilibrium, characteristic time and regression coefficient according to a monoexponential model. Values vs $T\left({ }^{\circ} \mathrm{C}\right)$

\begin{tabular}{c|c|c|c}
\hline$T\left({ }^{\circ} \mathrm{C}\right)$ & $\gamma_{\mathrm{eq}}(\mathrm{mN} / \mathrm{m})$ & $\tau$ & $R^{2}$ \\
\hline 20 & 23.4 & 909 & 0.913 \\
\hline 30 & 23.0 & 769 & 0.968 \\
\hline 40 & 18.3 & 588 & 0.963 \\
\hline 50 & 17.9 & 526 & 0.959 \\
\hline 60 & 17.5 & 556 & 0.948 \\
\hline
\end{tabular}

Then for our systems, a bi-exponential model was tentatively considered according to the following equation with $\tau 1$ and $\tau 2$ corresponding to characteristic time for the longest and shortest time, respectively.

$$
\gamma(t)=\gamma_{\mathrm{eq}}+A e^{-t / 12}+B e^{-t / 22}
$$

Calculations were made for the curve fitting at $40^{\circ} \mathrm{C}$ only. Variation of $\left(\gamma-\gamma_{\mathrm{eq}}\right)$ versus time for time over $300 \mathrm{~s}$ permit to calculate the parameters $A$ and $\tau 1$. Then variation of $\left(\gamma-\gamma_{\text {eq }}\right)-$ $A \exp (t / \tau 1)$ versus time for time less than $300 \mathrm{~s}$ permit to calculate the parameters $B$ and $\tau 2$ (Fig. 2). For each exponential, the characteristic time and regression time are noticed in Table 3.

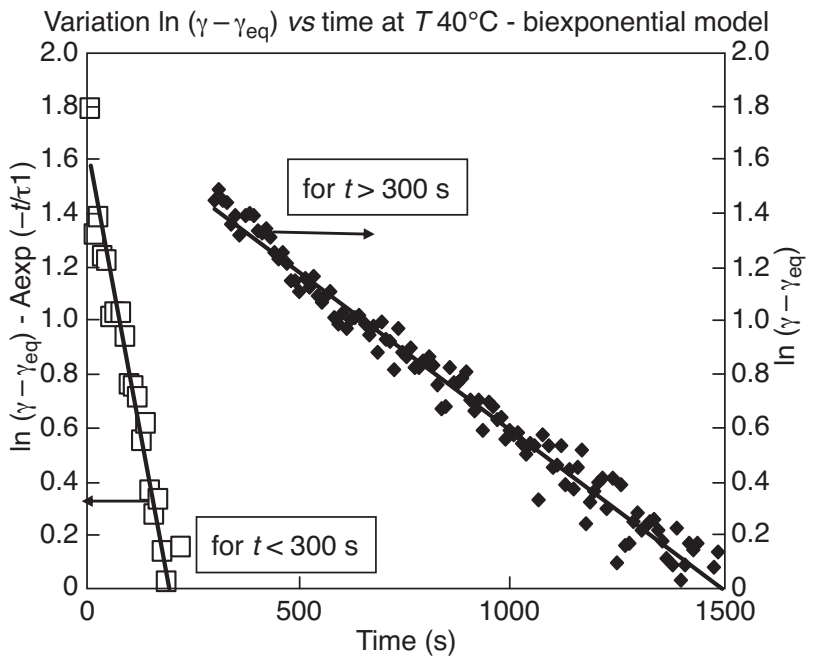

Figure 2

Curve profile of $\ln \left(\gamma-\gamma_{\mathrm{eq}}\right)$ vs time at $40^{\circ} \mathrm{C}$ considering bi-exponentiel model. 
TABLE 3

Interfacial tension at equilibrium, characteristic times and regression coefficient according to a bi-exponential model at $40^{\circ} \mathrm{C}$

\begin{tabular}{c|c|c|c}
\hline$T\left({ }^{\circ} \mathrm{C}\right)$ & $\gamma_{\mathrm{eq}}(\mathrm{mN} / \mathrm{m})$ & $A e^{-1 / \mathrm{t} 1}$ & $B e^{-1 / \mathrm{r} 2}$ \\
\hline $40^{\circ} \mathrm{C}$ & 18.3 & $\tau 1=833 \mathrm{~s}$ & $\tau 2=117 \mathrm{~s}$ \\
& & with $R^{2}=0.979$ & with $R^{2}=0.947$ \\
\hline
\end{tabular}

It should be noticed that the value of the longest time $\tau 1$ associated to asphaltene rearrangement at the interface is higher that the characteristic time $\tau$ issue from monoexponential model. The value of the shortest time $\tau 2$ is still too important to be directly attributed to a molecular diffusion process. Tentative modelling was tried using the classical law of Ward and Tordai that describes the diffusion controlled adsorption of surfactants at the interface [33]. At shortest time, Equation (7) was considered:

$$
\gamma(t)=\gamma_{0}-2 R T C(D t / \pi)^{1 / 2}
$$

with $R$ universal gas constant, $T$ temperature in ${ }^{\circ} \mathrm{K}, C$ bulk concentration of surfactant and $D$ diffusion coefficient. For the experiment at $40^{\circ} \mathrm{C}$ it was possible to fit the variation of the interfacial tension versus square root of time for time less than $200 \mathrm{~s} \mathrm{(Fig.} \mathrm{3)} \mathrm{with} \mathrm{a} \mathrm{regression} \mathrm{coefficient} R^{2}$ of 0.976 . The value of the diffusion coefficient is on the order of $6 \times 10^{-9} \mathrm{~cm}^{2} / \mathrm{s}$ considering the $0.1 \%$ of asphaltene concentration contained in the crude oil. In agreement with literature we assumed an asphaltene molecular weight of $5000 \mathrm{~g} / \mathrm{mol}$ with an average size of $2 \mathrm{~nm}^{2}$ [34]. Considering only Brownian motion a theoretical diffusion coefficient of asphaltene molecule by the well-known Einstein-Stokes law gives a value around $10^{-7} \mathrm{~cm}^{2} / \mathrm{s}$ with an oil viscosity of 0.01 Pa.s at $40^{\circ} \mathrm{C}$ [29]. With this order of magnitude of $D$ in comparison with the theoretical value, it is difficult to conclude from our experiment that the asphaltene adsorption at the interface is purely controlled by the molecular diffusion process.

The temperature effect on the reorganization process of the molecules at the interface was considered using the characteristic time calculated with Equation 5. The value of the interfacial tension at the equilibrium is taken when $\gamma$ is close to a plateau value. This characteristic time $\tau$ as well as the equilibrium interfacial tension $\gamma$ were plotted as a function of the inverse absolute temperature (Fig. 4) as well as the equilibrium tension. It is worth noticing that temperature seems to accelerate the reorganization process of the different molecules at the interface. Furthermore, the equilibrium interfacial tension decreases with temperature. It is possible to get an Arrhenius type fitting for both cases, where the activations energies are $6.8 \mathrm{~kJ} / \mathrm{mol}$ and $11.2 \mathrm{~kJ} / \mathrm{mol}$ for the reorganization time and the interfacial tension at equilibrium respectively. Value of these activation energies are on the order of magnitude of the value $(17.5 \mathrm{~kJ} / \mathrm{mol})$ found in a previous study on the same crude considering the viscosity variation [29].

\subsection{Kinetics of Film Formation}

The kinetics of film formation was followed by the evolution of the film viscoelastic properties (elastic $E$ ' and viscous $E$ " moduli) of a fresh droplet with time, at a fixed temperature and a pulsation frequency $(N)$. The evolution of $E^{\prime}, E^{\prime}$ and $\delta$ (phase angle) for $T=30^{\circ} \mathrm{C}$ and $N=0.1 \mathrm{~Hz}$ is shown in Figure 5.

The elastic modulus increases with time. The equilibrium is still not reached at 50000 seconds (about $14 \mathrm{~h}$ ). On the

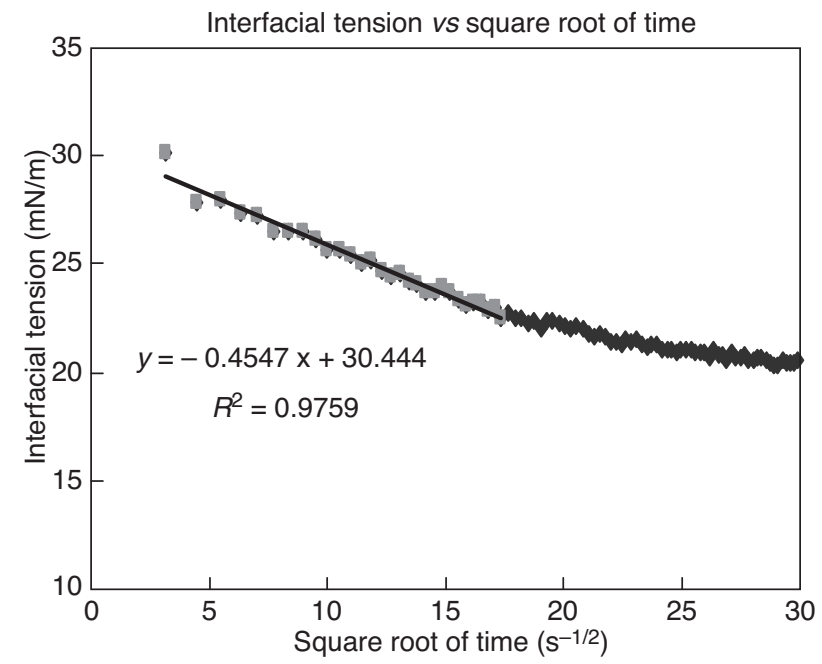

Figure 3

Interfacial tension $v s$ square root of time at $T 40^{\circ} \mathrm{C}$.

Characteristic time, interfacial tension at equilibrium vs $1 / T$

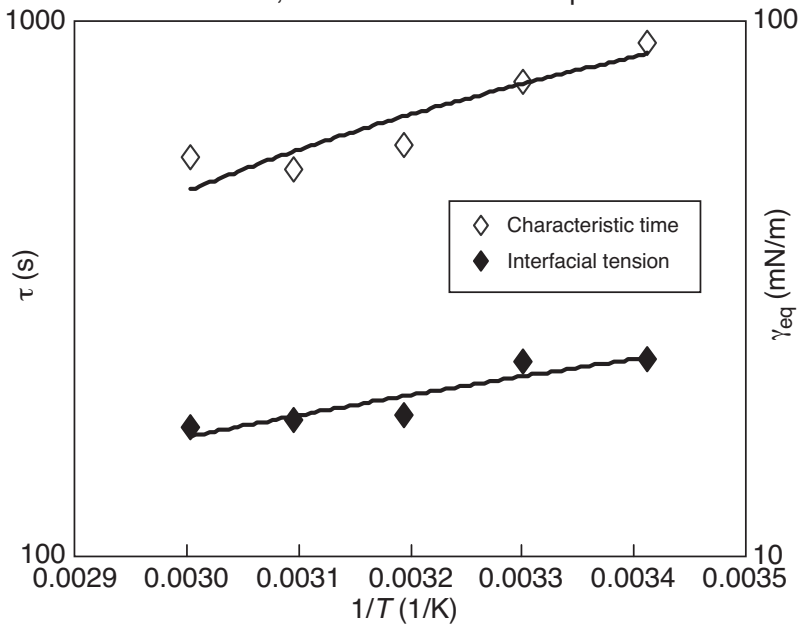

Figure 4

Characteristic times calculated according to monoexponential model (Eq. 5) and interfacial tension at equilibrium $v s 1 / T$ Arrhenius plot. 


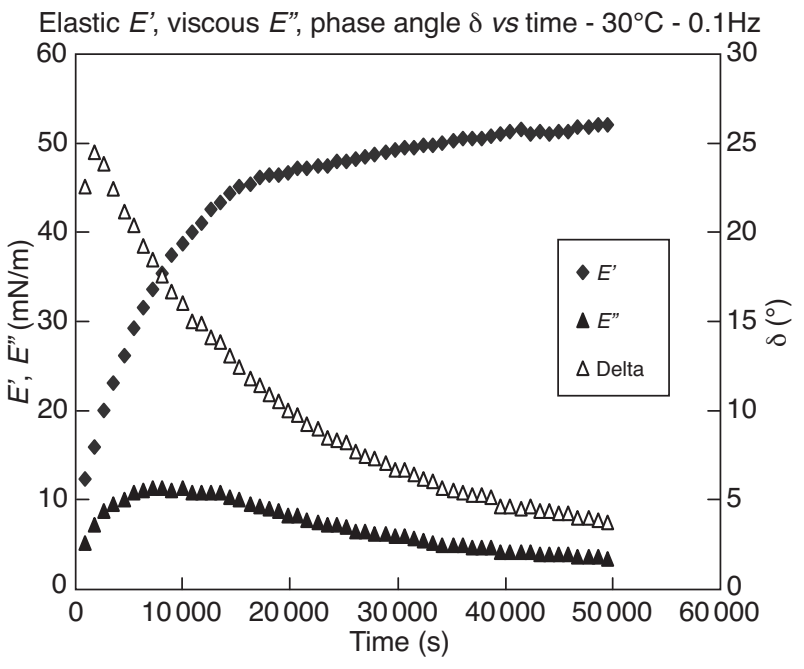

Figure 5

Elastic $\left(E^{\prime}\right)$, viscous $\left(E^{\prime \prime}\right)$ moduli and phase angle $(\delta) v s$ with time. $T=30^{\circ} \mathrm{C}, N=0.1 \mathrm{~Hz}$, fresh drop.

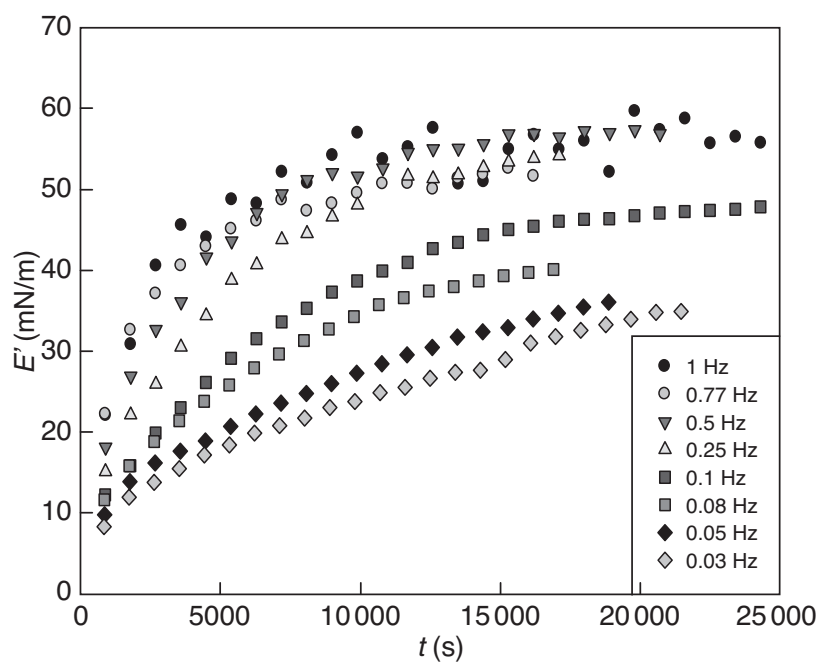

Figure 6

Elastic modulus $E$ ' evolution with time. $T=30^{\circ} \mathrm{C}$. Tests made with a fresh drop for each frequency condition. other hand, the viscous modulus decreases until low values (less than $4 \mathrm{mN} / \mathrm{m}$ ), as the phase angle (less than $4^{\circ}$ ). In all cases the elastic component is much higher than the viscous one: $E^{\prime}>E^{\prime \prime}$. This evolution indicated a molecule reorganization at the interface which elasticity increases with time, and surface's viscosity character decreases until reaching an only elastic behavior (similar to solid's Hooke behavior).

The former experimental procedure was applied using an interval of frequency pulsations $(0.03 \mathrm{~Hz}$ to $1 \mathrm{~Hz})$ given by the equipment in order to follow the effect of frequency on the evolution of viscoelastic properties in time at a fixed temperature. All the tests are shown in Figure 6, where the elastic modulus $E$ ' is plotted $v s$ time for a temperature of $30^{\circ} \mathrm{C}$ for a series of pulsation frequencies. For each frequency, a new fresh drop was used.

It is worth noting that for all frequencies, the elastic modulus increases with time, with a significant increase of the slope within the first two hours. Then values of $E$ ' seems to reach a plateau. In the same way the viscous modulus $E$ "' decreases with time at all the frequencies tested (for example, at $N=0.1 \mathrm{~Hz}$, Fig. 5) meaning that the increase of interface elasticity was corroborated for all frequencies. Also, from Figure 6 , it is possible to observe that $E$ ' increases with frequency for a fixed time. Nevertheless, for $N>0.25 \mathrm{~Hz}$ all the experimental data are superimposed.

The elastic modulus $v$ frequency is plotted at a fixed time in $\log$ - log scale (Fig. 7 and Fig. 8). For a time less than one hour, all curves are almost parallel and it is possible to fit the elastic modulus values as a power function of frequency: $E^{\prime} \propto N^{n}$. For all the times considered, the exponent $n$ was close to 0.3 with a regression coefficient of 0.99 for all curves (Tab. 4). Figure 8 shows the elastic modulus values versus frequency for time over than one hour. For the higher pulsation values, $E$ ' becomes almost independent of the frequency for frequency $>0.1 \mathrm{~Hz}$.

In the same way, the viscous modulus $E$ " was plotted versus frequency for a fixed time (Fig. 9). For $t<30$ minutes, viscous modulus variation is a power function of pulsation frequency with an exponent close to 0.3 and a regression coefficient around 0.96 in both cases (15 and 30 minutes). Beyond $30 \mathrm{~min}$, power fitting has a bad regression coefficient $\left(R^{2}<0.9\right)$. In the same Figure 8 , phase angle $(\delta)$ values are plotted as a function of frequency, for $t=15$ and 30 minutes. In this time range, phase angle $\delta$ values are approximately constant around $24^{\circ}$.

TABLE 4

Elastic modulus $E^{\prime} v$ s frequency $(t<1 \mathrm{~h})$ Exponent $n$ values at different time: $E^{\prime} \propto N^{n}$

\begin{tabular}{c|c|c}
\hline Time $(\mathrm{min})$ & $n$ & $R^{2}$ \\
\hline 15 & 0.28 & 0.992 \\
\hline 30 & 0.29 & 0.988 \\
\hline 45 & 0.30 & 0.999 \\
\hline 60 & 0.30 & 0.996 \\
\hline
\end{tabular}

A relaxation test experiment has been performed on a fresh drop. A rapid linear deformation on the drop was applied after 15 min which is the minimum time required for drop stability. Figure 10 shows the evolution after the surface 


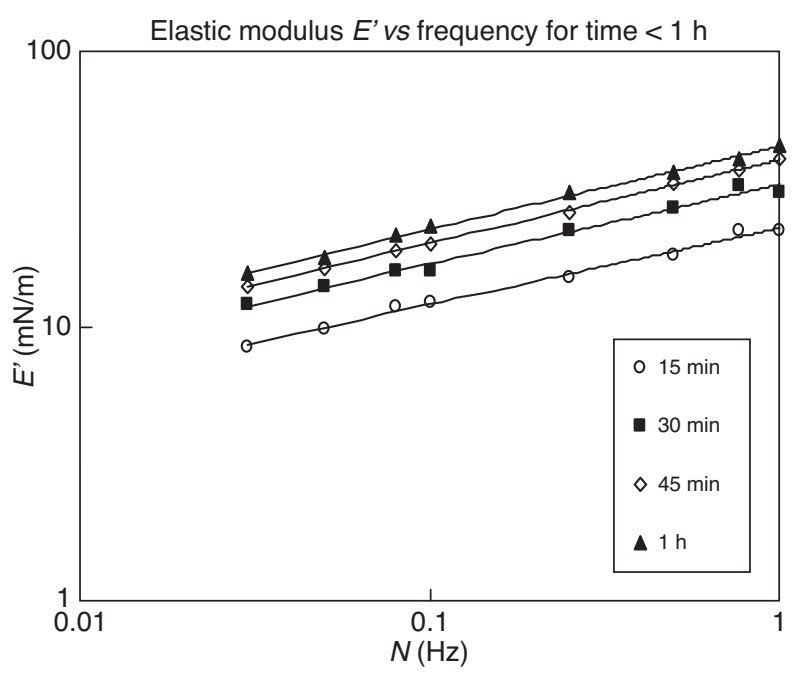

Figure 7

Elastic modulus $v$ frequency for different time $(t<1 \mathrm{~h})-T 30^{\circ} \mathrm{C}$ - fresh drop.

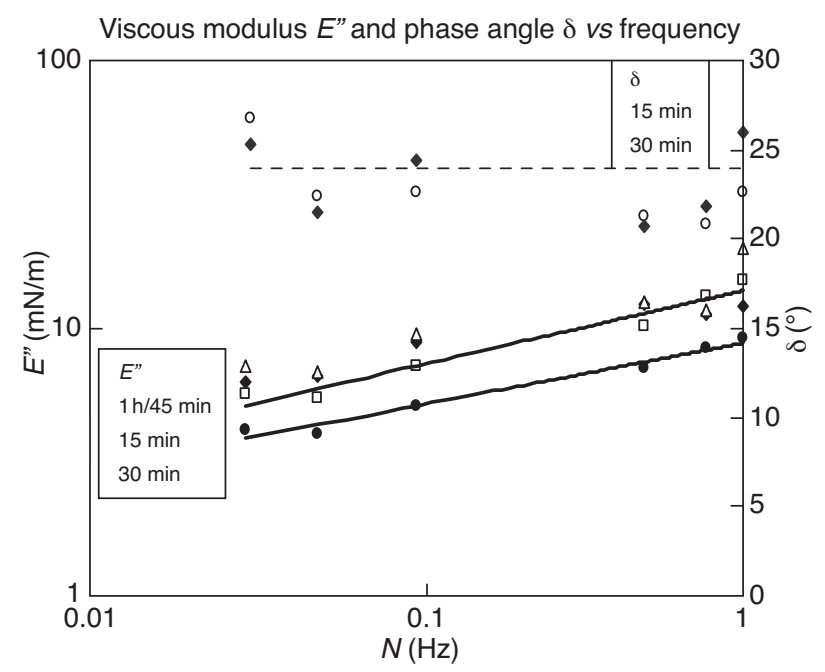

Figure 9

Viscous modulus $E^{\prime \prime}$ and phase angle $\delta v s$ frequency for different times $(t<1 \mathrm{~h})-T 30^{\circ} \mathrm{C}$ - fresh drop.

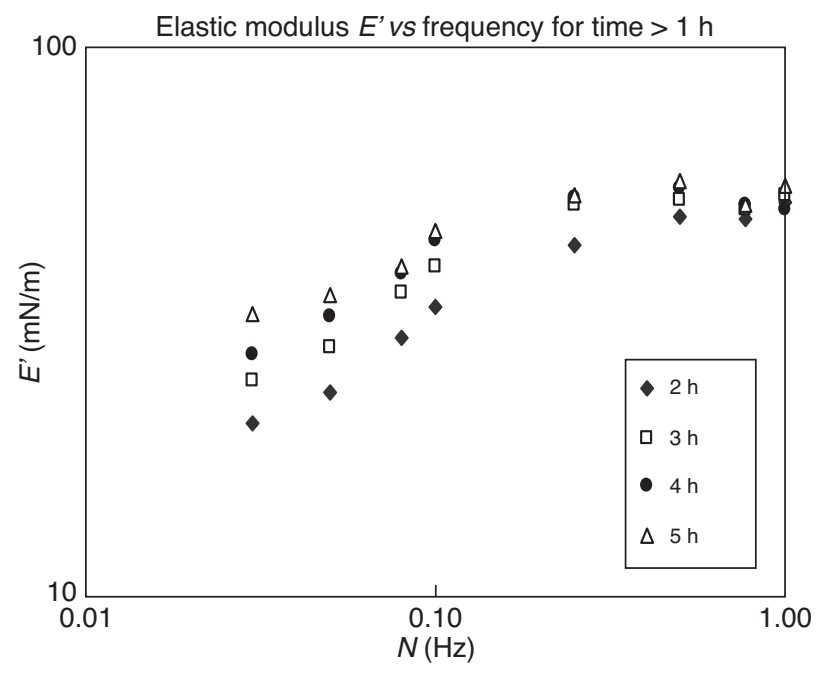

Figure 8

Elastic modulus $v s$ frequency for different times $(t>1 \mathrm{~h})-T 30^{\circ} \mathrm{C}$ - fresh drop.

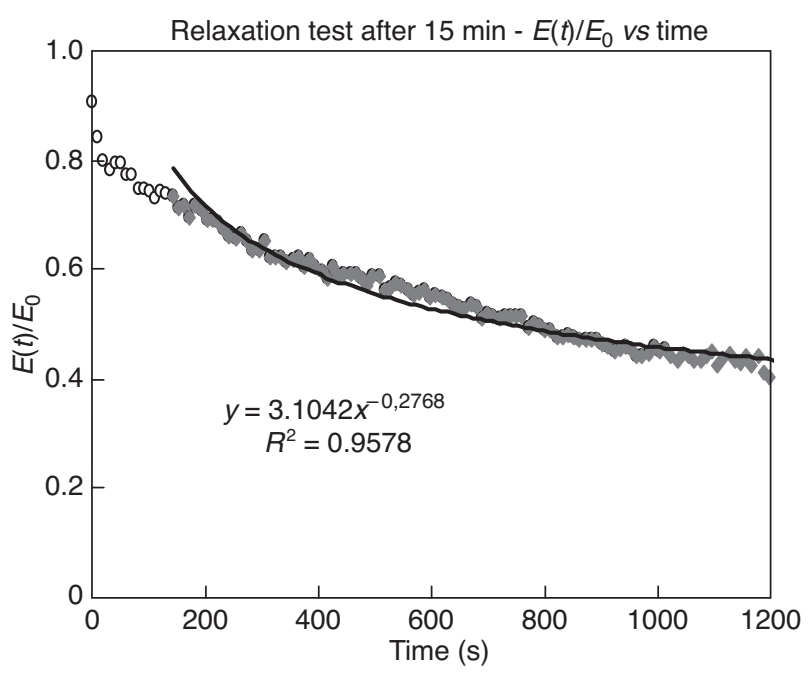

Figure 10

Normalized relaxation modulus - $E(t) / E_{0}$ as a function of time at $T=30^{\circ} \mathrm{C}$. Linear abrupt deformation of a fresh drop made after $t=15 \mathrm{~min}$. deformation of the relaxation modulus $(E)(E q .4)$ normalized with $E$ at $t=0\left(E_{0}\right)$ versus time. It is possible to adjust the interfacial decrease values to a power law $E(t) \propto t^{-n}$. An exponent close to 0.28 was found for a period of time over $100 \mathrm{~s}$ with a regression coefficient around 0.95. During this period of time not only the interface relaxed due to the initial deformation but also molecular re-organization occurred as presented in Figure 1.
In order to understand the behavior of the interface from our experimental results, the works and theory presented by Winter and Chambon has been considered [24, 25]. Based on experiments performed on macromolecules in solution, the authors defined the following criterion for "gel point" or organized molecular structure transition point which can be written as:

$$
E^{\prime} \propto N^{n}
$$


Elastic $E^{\prime}$, viscous $E^{\prime \prime}$ and phase angle $\delta$ vs frequency

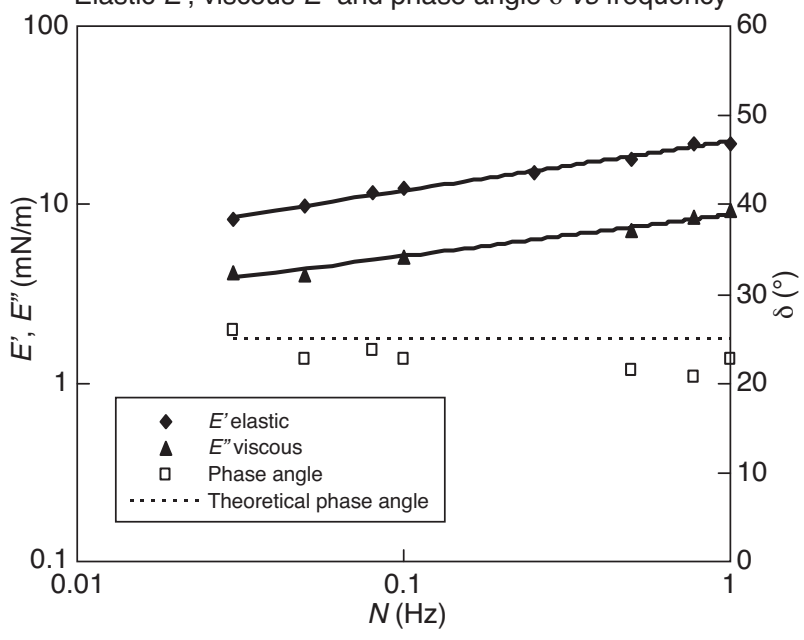

Figure 11

Elastic $E^{\prime}$, viscous $E^{\prime}$ moduli and phase angle $\delta v$ frequency at $T=30^{\circ} \mathrm{C}, t=15 \mathrm{~min}$ - fresh drop.

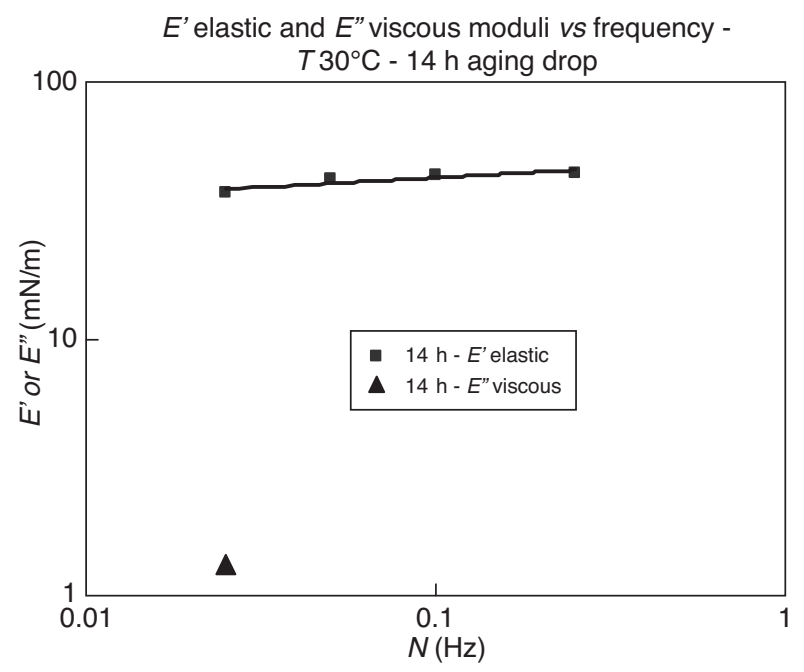

Figure 12

Elastic $E^{\prime}$ and viscous $E^{\prime \prime}$ moduli $v s$ frequency at $T=30^{\circ} \mathrm{C}$ $14 \mathrm{~h}$ aging drop.

$$
\begin{gathered}
E^{\prime} \propto N^{n} \\
\delta=n \frac{\Pi}{2} \\
E(t) \propto t^{-n}
\end{gathered}
$$

It can be observed from our data that:

- variations of the $E$ ', $E$ ' and $\delta$ satisfy Equations (8-10);

- for $E$ ' and $E$ " variation versus frequency, values of the exponent $n$ is 0.28 at $15 \mathrm{~min}$ and 0.29 at $30 \mathrm{~min}$;

- over a certain period of time, relaxation modulus $E$ varies according to Equation (11) with an exponent $n$ of 0.28 .

So, according to the criterion defined by Winter and Chambon, a molecular structure transition point of the interfacial film could be identified experimentally at $t=15 \mathrm{~min}$ (Fig. 10, 11) with an exponent of 0.28. Furthermore, in a qualitative sense, the visualization of a skin at the surface of droplet after a voluntary sudden volume reduction of the drop volume after 15 minutes of phases contact, confirms the formation of an organized structure at the droplet surface.

Recently Bouriat et al. [11] presented also the identification of the interface behavior according to the criterion defined by Winter and Chambon. Experiments were performed also on petroleum systems on model asphaltenes oil drops. These authors verified that Equations (8-10) were satisfied after 48 hours of contact between the oil drop and the aqueous phase. They used 11\% w/w asphaltenes model oil (asphaltenes in cyclohexane). It is worth noticing that they did not follow the film kinetics formation. In the same kind of study, Dicharry et al. [12] found this behavior for a $16 \mathrm{~h}$ aged interface of crude oil, desasphalted crude oil, and a heavy fraction of crude oil. All these oil phases were diluted in cyclohexane. They concluded that asphaltenes are not the only responsible of an organized structure at the interface, since they obtained the same behavior for the desasphalted crude oil. They have attributed this phenomenon to other heavy fractions of crude oil, like resins.

The results of Dicharry et al. may support the findings of this work, given the fact that the crude oil used in this study is very poor in asphaltenes $(0.1 \% \mathrm{w}$, Tab. 1$)$. Nevertheless, a structured film at the oil/water interface was identified with the interfacial rheological measurements. Thus, it seems possible that not only asphaltenes contribute to the interfacial film formation. Alternatively, the rheological study carried out on $\mathrm{W} / \mathrm{O}$ emulsions made from this crude oil, pointed out the extreme stability of these dispersed systems even at high volume fraction $(60 \% \mathrm{v})$ [29]. At the droplet surface and during interfacial film formation, interactions between asphaltenes and other molecules such as resins at the interface may be suspected.

\subsection{Remarks Concerning Long Time Effect on Interfacial Film Behavior}

In order to analyze the effect of interface aging, a crude oil drop was maintained for 14 hours in contact with the aqueous phase at $T=30^{\circ} \mathrm{C}$. After this period, on the same undisturbed drop, several sinusoidal deformations were applied $(8.7 \%$ or less of surface deformation) with different pulsation frequencies (Fig. 12). It is still possible to get a power fitting of elastic modulus $E$ 'versus frequency $N$ on the $14 \mathrm{~h}$ aged 


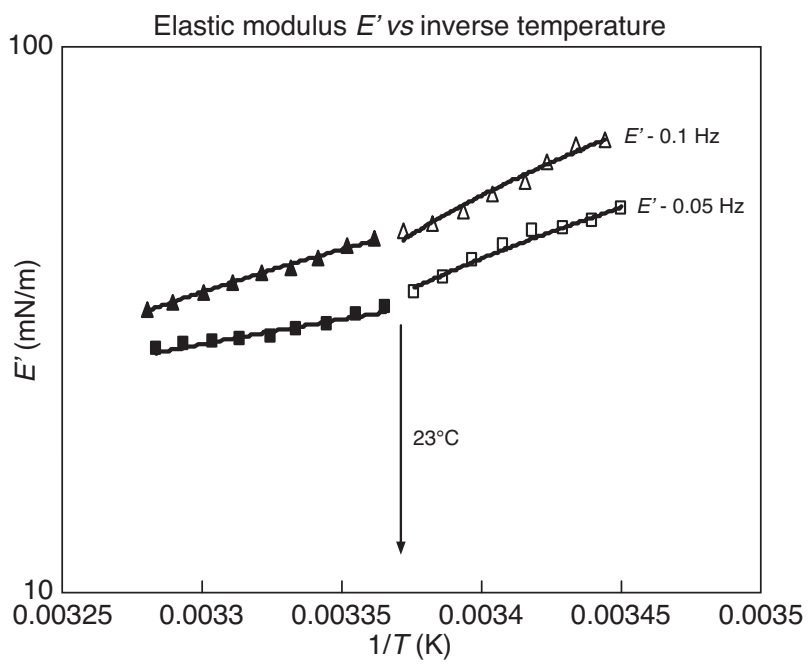

Figure 13

Elastic modulus $E^{\prime}$ vs $1 / T$ - Arrhenius plot - at two frequencies $(0.05 \mathrm{~Hz}$ and $0.1 \mathrm{~Hz})$ on a drop aged $14 \mathrm{~h}$.

drop but a very low exponent of 0.06 was obtained. For aging time over $14 \mathrm{~h}$, the elastic modulus $E$ ' is almost independent of frequency. Furthermore, the viscous modulus $E$ " exhibits very low values (around $1 \mathrm{mN} / \mathrm{m}$ ), reaching the accuracy limit of the apparatus at the higher frequencies. The nearly constant value of the elastic modulus and low value of the viscous modulus seems to indicate that, after the aging period of $14 \mathrm{~h}$, the interfacial film is quite stabilized and behaves as a pure elastic film.

A temperature scan was applied for a drop aged of $14 \mathrm{~h}$, which was maintained at $15^{\circ} \mathrm{C}$. After this period of time, a temperature gradient was applied $\left(1^{\circ} \mathrm{C} / 15 \mathrm{~min}\right)$, and simultaneously the drop was sinusoidally deformed: one test at a pulsation frequency of $0.1 \mathrm{~Hz}$ and another test at a pulsation of $0.5 \mathrm{~Hz}$. Results of elastic modulus $E$ ' for both frequencies are plotted $v s$ absolute temperature inversed $1 / T(\mathrm{~K})$ as shown in Figure 13. In this case, with the temperature's increase, the elastic modulus decreases. That confirms the classical behavior where the elastic character is destroyed by thermal molecular agitation. At fixed temperature in the temperature range studied, the elastic modulus $E^{\prime}$ was lower for the lower frequency $(0.5 \mathrm{~Hz})$ as expected.

It is possible to fit $E$ ' values with an Arrhenius type equation, considering two temperature ranges. The temperature behavior limit has been related to the paraffins' precipitation threshold at $T=23^{\circ} \mathrm{C}(300 \mathrm{~K})$, which was found also in a previous study for this crude oil, using bulk rheology measures [29].

\section{CONCLUSIONS}

By means of interfacial oscillatory rheological measures, it was possible to determine the values of elastic and viscous moduli of the interfacial film of a crude oil/saline water drop. The kinetics of the film formation was studied on a fresh drop regularly oscillated at different frequencies. Monitoring in time the viscoelastic properties of the interfacial film, after 15 minutes, our experimental measures verified the criterion proposed by Winter and Chambon for the formation of an organized molecular structure.

\section{ACKNOWLEDGEMENTS}

Authors wish to thank IFP for the permission to publish.

\section{REFERENCES}

1 Schramm L.L. (Ed.) (1992) Emulsions: Fundamentals and Applications in the Petroleum industry, Adv. Chem. Ser. 231, ACS, Washington DC.

2 Sjoblom J., Aske N., Auflem I.H., Brandal O., Havre T.E., Sæther O., Westvik A., Johnsen E.E., Kallevik H. (2003) Our current understanding of water-in-crude oil emulsions. Recent characterization techniques and high pressure performance, $A d v$. Colloid Interfac. 100-102, 399-473.

3 Spiecker P.M., Kilpatrick P.K. (2004) Interfacial Rheology of Petroleum Asphaltenes at the Oil-Water Interface, Langmuir 20, 4022-4032.

4 Graham D.E. (1988) Crude Oil Emulsions: Their Stability and Resolution, Spec. Publ. R. Soc. Chem. (Chem. Oil Ind.) 67, 155-175.

5 Papirer E., Bourgeois C., Siffert B., Balard H. (1982) Chemical Nature and Water/Oil Emulsifying Properties of Asphaltenes, Fuel 61, 732-734.

6 Bridié A.L., Wanders T.H., Zegveld W., Van der Heidge H.B. (1980) Formation, Prevention and Breaking of Seawater in Crude Oil Emulsions 'Chocolate Mousses', Mar. Pollut. Bull. 11, 343-348.

7 Salager J.L. (1990) The fundamental basis for the action of a chemical dehydratant: Influence of Physical and Chemical formulation on the stability of an emulsion, Ind. Chem. Eng. 30, 103-116.

8 Langevin D. (2000) Influence of interfacial rheology on foam and emulsion properties, Adv. Colloid Interfac. 88, 209-222.

9 Kim Y.H., Wasan D.T., Breen P.J. (1995) A study of dynamic interfacial mechanisms for demulsification of water-in-oil emulsions, Colloid. Surface A 95, 235-247.

10 Bauget F., Langevin D., Lenormand R. (2001) Dynamic Surface Properties of Asphaltenes and Resins at the Oil/Air Interface, $J$. Colloid Interf. Sci. 239, 501-508.

11 Bouriat P., El Kerri N., Graciaa A., Lachaise J. (2004) Properties of a Two-Dimensional Asphaltene a Network at the WaterCyclohexane Interface Deduced from Dynamic Tensiometry, Langmuir 20, 7459-7464.

12 Dicharry C., Arla D., Sinquin A., Graciaa A., Bouriat P. (2006) Stability of Water/Crude Oil Emulsions based on Interfacial Dilatational Rheology, J. Colloid Interf. Sci. 297, 785-791. 
13 Yarranton H.W., Sztukowski D.M., Urrutia P. (2007) Effect of Interfacial rheology on Model Emulsion Coalescence-Interfacial Rheology, J. Colloid Interf. Sci. 310, 246-252.

14 Hannisdal A., Orr R., Sjöblom J. (2007) Viscoelastic Properties of Crude Oil Components at Oil-Water Interfaces. 1: The Effect of Dilution, J.Disper. Sci. Technol. 28, 1.

15 Freer E.M., Wong H., Radke C.J. (2005) Oscillating drop/ bubble tensiometry: effect of viscous forces on the measurement of interfacial tension, J. Colloid Interf. Sci. 282, 128-132.

16 Freer E.M., Radke C.J. (2004) Relaxation of asphaltenes at the toluene/water interface: Diffusion exchange and surface rearrangement, J. Adhesion 80, 6, 481-496.

17 Jones T.J., Neustadter E.L., Whittingham K.P. (1978) Water-inCrude Oil Emulsion Stability and Emulsion Destabilization by Chemical Demulsifiers, J. Can. Petrol. Technol., 100-108.

18 Zhang L.Y., Xu Z., Masliyah J.H. (2005) Characterization of Adsorbed Athabasca Asphaltene Films at Solvent-Water Interfaces using a Langmuir Interfacial Trough, Ind. Eng. Chem. Res. 44, 1160-1174.

19 Acevedo S., Escobar G., Gutierrez L.B., Rivas H., Gutierrez X. (1993) Interfacial Rheological Studies of Extra-Heavy Crude Oils and Asphaltenes: Role of the Dispersion Effect of Resins in the Adsorption of Asphaltenes at the Interface of Water-in-Crude Oil Emulsions, Colloid. Surface A 71, 65-71.

20 Mohammed R.A., Bailey A.I., Luckham P.F., Taylor S.E. (1994) The Effect of Demulsifiers on the Interfacial Rheology and Emulsion Stability of Water-in-Crude Oil Emulsions, Colloid. Surface A 91, 129-139.

21 Daniel-David D., Pezron I., Clausse D., Dalmazzone C., Noïk C., Komunjer L. (2004) Interfacial properties of a silicone copolymer demulsifier at the air/water interface, Phys. Chem. Chem. Phys. 6, 1570-1574.

22 Daniel-David D., Pezron I., Clausse D., Dalmazzone C., Noik C., Komunjer L. (2005) Elastic properties of crude oil/water interface in presence of polymeric emulsion breakers, Colloid. Surface A 270-271, 257-262.

23 Winter H.H., Chambon F. (1986) Analysis of Linear Viscoelasticity of a Crosslinking Polymer at the Gel Point, $J$. Rheol. 30, 367-382.
24 Chambon F., Winter H.H. (1987) Linear Viscoelasticity at the Gel Point of a Crosslinking PDMS with Imbalanced Stoichiometry, J. Rheol.31, 683-697.

25 Ese M.E., Sjöblom J., Fordedal H., Urdahl O., Ronningsen H.P. (1997) Ageing of Interfacially Active Components and its Effect on Emulsion Stability as Studied by Means of High Voltage Dielectric Spectroscopy Measurements, Colloid. Surface A 123124, 225-232.

26 Wilde P.J. (2000) Interfaces: their role in foam and emulsion behavior, Curr. Opin. Colloid In. 5, 176-181.

27 Freer E.M., Kam Sub Yim, Fuller G.G., Radke C.J. (2004) Shear and dilatational relaxation mechanisms of globular and flexible proteins at the hexadecane/water interface, Langmuir 20, 1015910167.

28 Benjamins J., Cagna A., Lucassen-Reynders E.H. (1996) Viscoelastic Properties of Triacylglycerol/Water Interfaces Covered by Proteins, Colloid. Surface A 114, 245-254.

29 Quintero C., Noïk C., Dalmazzone C., Grossiord J.L. (2008) Modeling and characterization of diluted and concentrated water-in-crude oil emulsions: comparison with classical behaviors, Rheol. Acta 47, 4, 417-424.

30 Rousseau D., Hodge S.M. (2005) Stabilization of water-in-oil emulsions with continuous phase crystals, Colloid. Surface A 260, 229-237.

31 Serrien G., Geeraerts G., Gosh L., Joos P. (1992) Dynamic surface properties of adsorbed protein solutions: BSA, casein and buttermilk, Colloids Surfaces 68, 219.

32 Jeribi M., Almir-Assad B., Langevin D., Henaut I., Argillier J.F. (2002) Adsorption Kinetics of Asphaltenes at Liquid Interfaces, J. Colloid Interf. Sci. 256, 268-272.

33 Ward A.F.H., Tordai L. (1946) Time-Dependence of Boundary Tensions of Solutions. I. The role of diffusion in time-effects, $J$. Chem. Phys. 14, 7, 453-461.

34 Jestin J., Simon S., Zupancic L., Barré L. (2007) A small angle neutro scattering study of the adsorbed asphaltene layer in waterin-hydrocarbon emulsions: Structural description related to stability, Langmuir 23, 10471-10478.

Final manuscript received in March 2009 Published online in July 2009 or distributed for profit or commercial advantage and that copies bear this notice and the full citation on the first page. Copyrights for components of this work owned by others than IFP must be honored. Abstracting with credit is permitted. To copy otherwise, to republish, to post on servers, or to redistribute to lists, requires prior specific permission and/or a fee: Request permission from Documentation, Institut français du pétrole, fax. +33147527078 , or revueogst@ifp.fr. 